\title{
COVID-19: Today's Ambiguity, Tomorrow's Uncertainty and After Tomorrow's Questions
}

The daily facts of COVID-19 developments and progress, yielded amazing data, particularly that one related to the biological feature of the virus, and its rapid incursion nature, despite all the procedures applied. It is obvious that COVID-19 disrupted the entire world from the economic, social, and functional points of concern, or what relates to the consequences of the damages, the world is going to witness the future wisely. Both the extent of damages as well as nature shall pigment the foreseeable future. Prospectively, we can say that the whole world infrastructure is shaking and its givens are going to changing with the unrecognized speed in relation to this dilemma.

\section{Unique challenges}

At the time being, and in the lack of a vaccine and of particular medications of proven efficacy against COVID-19 infection, the only unique and effective measures, to adopt are preventative, such as social distancing protocols. The experience of countries like the USA, Spain, and Italy, the most devastatingly affected by the worldwide pandemic, can be a model for the other European countries that followed in facing the outbreak. The power of social isolation in Italy is reflecting now in terms of reduction of symptomatic cases requiring hospitalization. Nevertheless, there are still many observations need an explanation. For instance, the highest spread of the infection might be due to the high population density or other, yet unknown, factors.

An intelligent and smart investment in both fundamental research and public health is crucial if we are approaching a deep understanding of this aggressive and explosive Virus. Furthermore, developing science-based policies to address it comes to be a necessity. Part of that anxiety is rooted in the uncertainty, as we still have many unanswered questions so far: basic available information about the virus is inadequate at the time being, and not enough about how coronavirus will act in the future.
Now, at the present time, efforts are rightly focused on urgent issues like securing individuals and population protection, supplying emergency equipment and ventilators. We need furthermore research, to be able to win the field battle we. The understanding enemy shall be a key to victory, it will offer better diagnosis, treatment, and prevention will become a reality.

In recent memory, rarely has it been this difficult to look beyond the next day.... yet this is what exactly, we need to do, the world has no time to Wait. To see the light on the other end and the way past this crisis. To advance a step ahead of the next one- we need to operate in two types of investigations that will answer some gaped questions. Exploring questions of fundamental basic science, like how novel viruses like the coronavirus operate within the human body, extending to the cellular level, and examining the way a virus spreads throughout the population, utilizing public health research to inform the policies presently implemented at the local and national level.

\section{Future Questions}

It is a mandate of fundamental research to address:

-The exact time an individual infected with the coronavirus becomes contagious.

-What factors making the infected person becomes symptomatic?

- In asymptomatic person, what makes him contagious without coughing, sneezing?

- How infectious droplets generated?

- Why infection spread when an individual is becoming symptomatic.

- In case of serious complications, dose the person contagious for a longer period?

- How to establish science-based policies for lifting "stay at home" restrictions.

- How to improve the control of the spread of disease both for today and in the future. 
It is the mandates of Public Health Research to address:

-How social factors can affect a virus's impact.

-Does experiencing social factors affect person risk?

-How can we protect vulnerable communities such as people who are homeless, imprisoned, or poor?

-How to understand social complexity in COVID-19 context.

-How to utilize social modelling to breakdown the transmission chain.

Obtaining these answers will significantly tell how we dedicate future resources. Research Commitment for Long-term will affect our future now more than ever; engaging in both areas of research shall be critical investment nationally, regionally, and globally. In spite of generous financial supports pushed in the national health system worldwide, funding has increased and the CARES Act includes additional funding for vaccine development, it seems, there is still a high need for further support in a sustainable manner for continuous expansion. Greater National Science Foundation funding is needed to address our fundamental science questions. CDC funding is critical to adequately address population health. With greater investment in research and the ongoing great work of public-private partnerships, It appears that major questions can be answered we have today and get ahead of those that will occur tomorrow.

\section{Where do we need to move?}

With all effort made in time and place that have been adopted to try and counteract the spread of the virus, it is still not clear how to draw a clear epidemiological map of the diseases to assess the amount of exposure in linking to a proportion of cases converted to positive, amongst these cohorts, and the proportion of individuals who become symptomatic and, most significantly, the proportion of mortalities. The correlation between the spreading of COVID-19 and the density of the population still needs gap investigation, root analysis, and further hypothesis testing. The potential impact of other environmental factors, as well as other confounders, (e.g., air pollution), does not have at present a clear scientific basis.

\section{Stepping Forward}

Social isolation strategy, which is widely applied in COVID-19 pandemic, made a significant difference in reducing morbidities and mortalities at this particular time, yet it was not passing without devastating effects on social and economic outcomes, that is why dealing with COVID-19 in the foreseeable future needs more effective preventive and therapeutic strategy but less devastating consequences on social and economic life. Epidemiological changes could be monitored in the future, putting into consideration the potential routes of spreading and subclinical infections, furthermore to adaptation, evolution, and spread of the virus amongst humans, intermediate host animals, and other reservoirs. The overall spectrum of the COVID-19 infection (proportion of cases found positive, those who revealed symptoms, that required hospital admission, and those who need intensive care and assisted ventilation, and those who die) may have been assessed by studies in small areas where the entire population can be been tested for infection. The medical registry of family doctors, General Practitioner, and other medical staff, who are currently at the front line of clinical care delivery in several worldwide countries, can be utilized retrospectively to identify the disease patterns and profiles in representative samples of the general population. Coming epidemiological and public health studies should be also performed in cohorts of patients who revealed symptoms and signs of COVID-19 infection, to assess the occurrence of any neurological and/or psychiatric features even after the present pandemic has over.

\section{REFERENCES:}

1. Beghi E. Berekzcki D. The COVID-19 Pandemic in Europe: Challenges, Unanswered Questions, And Future Steps: A message from the EAN Epidemiology. EAN pages (Online Article). Available from: https://www.eanpages.org/2020/04/02/the-COVID-19 -pandemic-in-europe-challenges-unansweredquestions-future-steps-a-message-from-the-eanepidemiology-panel/ [Last accessed on $21^{\text {st }}$ April, 2020] 2. Skorton DJ. To address COVID-19 and future pandemics, we must answer fundamental questions. AAMC (Online Article). Available from: https://www.aamc.org/news-insights/addressCOVID-19-and-future-pandemics-we-must-answerfundamental-questions [Last accessed on $21^{\text {st }}$ April, 2020]

3. McNulty M. Coping with Uncertainty during COVID-19: An International Gottman Trainer Shares Their Perspective. The Gottman Institute (Online Article). Available From: 
https://www.gottman.com/blog/coping-withuncertainty-during-COVID-19-an-internationalgottman-trainer-shares-their-perspective] [Last accessed on $21^{\text {st }}$ April,2020] 4. Baggio M. Here's why society is reacting with panic to coronavirus. World Economic Forum (Online Article). Available From: https://www.weforum.org/agenda/2020/o3/dontpanic-how-human-behaviour-can-fuel-thecoronavirus/. [Last accessed on $21^{\text {st }}$ April, 2020] 5. Ledford H. How does COVID-19 kill? Uncertainty is hampering doctors' ability to choose treatments. Nature (Online Article). Available from: https://www.nature.com/articles/d41586-020-01056-7 [Last accessed on $21^{\text {st }}$ April, 2020]

Cite this article as:

Hussain HY. COVID-19: Today's Ambiguity, Tomorrow's Uncertainty and After Tomorrow's Questions. Int Healthe Res J. 2020;4(1):1-3. https://doi.org/10.26440/IHRJ/0401.01338 